\title{
Un acercamiento al interés por la viticultura en el siglo XıX: a propósito de la traducción a francés del Ensayo sobre las variedades de la vid común que vegetan en Andalucía de Simón Clemente y Rubio
}

\author{
An approach to the nineteenth century interest about wine \\ growing: considerations about the translation into French \\ of Simón Clemente y Rubio's Ensayo sobre las variedades \\ de la vid común que vegetan en Andalucía in France
}

\author{
Francisco Luque Janodet \\ Universidad de Sevilla \\ fljanodet@us.es
}

\begin{abstract}
During the eighteenth and nineteenth centuries, the Spanish science has been characterized as a dependent science of the researches and scientific discoveries in Europe, especially those proceeding from France, one of the most prominent countries in the continent at the cultural and scientific level. In this context, the needs to have access to these discoveries and researches provoked an augmentation of the translation in Spain. Nevertheless, some treatises originally written in Spanish acquired relevance and prestige in Europe, among which it is found Simón de Rojas Clemente y Rubio's Ensayo sobre las variedades de la vic común que vegetan en Andalucia. This paper focuses the reception and the translation of this book in France, having into account the interest of enology as an emergent science during the nineteenth century.
\end{abstract}

\begin{abstract}
Résumé
La science espagnole s'est caractérisée, tout au long du XVIII ${ }^{e}$ et $\mathrm{XIX}^{\mathrm{e}}$ siècle, comme une science dépendante des recherches et des progrès scientifiques produits en Europe, spécialement ceux survenus en France, pays qui possédait le rang de phare culturel et chercheur de l'époque, condition accrue par sa proximité géographique avec l'Espagne. De cette manière, la nécessité de connaître les différents progrès et découvertes étrangers a provoqué une augmentation de l'activité traductrice dans le pays ibérique. Cependant, certains traités rédigés originalement en espagnol ont acquis une grande relevance et prestige en Europe, parmi lesquels on trouve l'ouvrage Ensayo sobre las variedades de la vic común que vegetan en Andalucía de Simón de Rojas Clemente y Rubio. Le présent article aborde la réception dudit ouvrage en France et sa traduction en français, compte tenu du grand intérêt dont jouissait l'œnologie en tant que science émergente durant le $\mathrm{XIX}^{\mathrm{e}}$ siècle.
\end{abstract}


Anales de Filología Francesa, n. ${ }^{\circ}$ 27, 2019

UN ACERCAMIENTO AL INTERÉS POR LA VITICULTURA EN EL SIGLO XIX: A PROPÓSITO DE LA...

\section{Key-words}

winegrowing treatise, scientific, dissemination, translation.

\section{Mots-clés}

traités viticoles, divulgation de la science, traduction.

\section{Introducción}

La vitivinicultura es uno de los ámbitos de la agronomía más estudiados desde hace siglos. Por esta razón, existen numerosos tratados centrados en distintos aspectos como, por ejemplo, la mejora de las técnicas de poda y de los cuidados de la vid, así como la simplificación de los procesos de vinificación. Asimismo, especialmente a partir del siglo XIX, comenzamos a encontrar obras que abordan distintas temáticas relacionadas con el ámbito vitivinícola como la cata del vino, su terminología y la sumillería. De hecho, parte del interés del vino radica en el interés sociocultural de esta bebida, especialmente palpable en las culturas de la cuenca mediterránea, con ejemplos como el Libro de agricultura de Abú Zacarías Al-Awwan, escrito durante el período de dominación musulmana en la península Ibérica en el siglo XIII, en el cual se consagran ciertas partes al cuidado de la vid y a los usos del vino. Más adelante, encontramos otros ejemplos como el tratado Liber de vinis, atribuido a Arnaldo de Vilanova, datado en el siglo XIV y considerado como un compendio de recetas de vinos medicinales; así como la obra Agricultura general de Alonso de Herrera (1513), cuyo segundo libro está dedicado al cultivo de la vid y a la elaboración del vino, siendo, de acuerdo con Ibáñez Rodríguez (2017: 22) “el primero de los escritos en español sobre la materia” y en el que nos encontramos, de acuerdo con este autor (ibid.):

[...] un primer estado del español del vino, de carácter patrimonial y tradicional. Alonso de Herrera habla en su tratado, por ejemplo, de hervir y cocer, para referirse a lo que más tarde el científico llamará fermentación. Nos encontramos en un estadio precientífico del español del vino.

Asimismo, hallamos en Francia otras obras como L'avant-goust du vin. Déclaration de sa nature, faculté medicinale et alimentaire de Engelbert Lamelin (1630) y ya, en los siglos XVIII y XIX, el Cours complet d'Agriculture ou dictionnaire universel de Rozier (1783) y L'Art de faire le vin (1807) de Cadet de Vaux, considerado como el primer tratado de enología. En España, a pesar del atraso de las ciencias con respecto al continente europeo, comienzan a darse, a partir del siglo XVIII, los primeros pasos que darían lugar a la enología (Bajo Santiago, 2006: 169) con obras como la Memoria de Francisco Cónsul Jove (1786) la cual, de acuerdo con Ibáñez (2017), es uno de los primeros textos enológicos en español. Más adelante, en sintonía con las aportaciones de Rozier y Cadet de Vaux, se publicará el tratado Arte de hacer y conservar el vino (1820) de Francisco Carbonell y Bravo, la primera obra enológica de este tipo en lengua castellana (Ibáñez, 2017).

De esta manera, dentro de la historia de los estudios del vino, debemos distinguir, 
como señala Peynaud (1988), la "historia de la enología" de la "historia de la vinificación", dado que se encuentran en planos distintos y divergen en su antigüedad. De hecho, para este autor (ibid.), existe un "periodo pre-enológico" en el que la elaboración del vino estuvo al margen de la ciencia, y un periodo de "enología científica", contemporánea a "los procesos de la química y de las primeras teorías sobre las causas de la fermentación y las enfermedades de los vinos". Precisamente, los resultados de Pan-Montojo (1989: 12) ponen de relieve esta realidad, ya que:

Entre 1770 y la publicación del Diccionario de Rozier, nació en Francia la enología, que, pese a que fue objeto de atención preferente de todos aquellos que estudiaron el cultivo de la vid, dependía mucho más estrechamente de la química para conseguir cambios substanciales.

Esta relación queda, a su vez, puesta de manifiesto en las palabras de Castellet (1865: 42), quien, a propósito de la relación de dependencia de la enología para con la química, señalaba que:

Esta parte tan interesante de la Enologia [sic] llama hoy la atención de los químicos modernos. Estudiada la composición atómica de todos los éteres que se producen en los vinos durante su largo y admirable trabajo de organización, se ha logrado ya obtenerlos separadamente, y muchos de ellos sin necesidad de concurrir a su formación las menores cantidades de vino. [...] Entretanto, y mientras la Química Orgánica va arrojando cada día nueva luz sobre este punto, veamos como debemos conducirnos en la elaboración de vinos superiores.

Por tanto, la evolución de la enología vendrá de la mano de los avances en la química (Bajo, 2006) y de las aportaciones foráneas, especialmente a partir del siglo XVIII (Pinilla y Lépinette, 2009: 111), pero, además, se inscribirá en la época de surgimiento de las lenguas de especialidad, entre los siglos XVII y XVIII (Ibáñez, 2017:22), donde comenzarán a plantearse, además, debates en torno a la traducción de la nueva terminología. Francia, por su condición de potencia europea y de cuna de la enología será el principal emisor de terminología especializada en el ámbito vitivinícola y el francés se convertirá en la lingua de este ámbito, como ya lo era de la medicina. A pesar del innegable peso de la enología francesa, España realizará aportaciones a esta ciencia con obras como la ya citada Memoria de Cónsul Jove (1786), con la edición de tratados agrícolas como los de Herrera por la Real Sociedad Matritense en 1818, y el Ensayo sobre las variedades de la vid común que vegetan en Andalucía (1807), tratado capital de carácter vitícola que gozó de gran prestigio en la Europa decimonónica, siendo traducido varios años después a francés y a alemán. 


\section{EI traductor de textos vitivinícolas en el siglo XIX}

La divulgación de la enología en el siglo XIX se vio favorecida por su concepción como un recurso que permitía la mejora de la calidad del vino entre los fabricantes y enólogos. Esta concepción determinó el comienzo de una serie de publicaciones con textos claros, sencillos y prácticos que sirviesen de guía a los productores de vino (Bajo, 2006). Esto se ve reflejado en las conclusiones de los estudios de Pan Montojo (1989) quien señala que, en los últimos veinticinco años del siglo XIX "salieron de la imprenta prácticamente el doble de libros sectoriales que en toda la etapa de 1750-1875". No obstante, no debemos olvidar que el atraso científico y tecnológico de España la convertían en una nación dependiente de la actividad traductora. Precisamente, Jiménez y Lépinette (2016: 111), en un estudio sobre la recepción de las obras médicas extranjeras a España en la primera mitad del siglo XIX, constatan que, en su corpus, suele aparecer señalado en la obra que el lector español tiene entre sus manos es una traducción, indicándose, por ello, el nombre y el cargo de la persona encargada de su traducción. Si bien es cierto que en varias de las traducciones inventariadas por estas autoras se omite información sobre la identidad del traductor, para lo cual han planteado varias hipótesis como que: 1) la identidad del traductor no añade valor a la traducción al no ser un personaje conocido; 2) el propio traductor no consideró conveniente firmar la traducción; 3) se trata de una temática médica alejada de la ciencia; 4) la obra es una reelaboración de un texto del que únicamente quedan algunas partes originales y, por tanto, realmente traducidas. Esto constata que el oficio del traductor estaba empezando a ser tenido en cuenta en España, sobre todo tras la creación de la Secretaría de Interpretación de Lenguas, surgida como órgano auxiliar del Consejo de Estado de Carlos v en 1527, la cual surge en un entorno renacentista, multicultural y multilingüe (Álvarez Jurado, 2016). Esta institución, permitió que, en España, además:

Un gran número de traductores con buena formación lingüística se dedicaron a la traducción de todo tipo de documentos. Sin embargo, otros tantos traductores (y estos son los que en esta ocasión nos interesan) se dedicaron exclusivamente a la traducción de textos científicos, y es necesario destacar la encomiable labor que ejercieron en la difusión del conocimiento científico en otros idiomas (Álvarez Jurado, 2016).

En lo que respecta a la terminología especializada, como señalan Bertomeu Sánchez y Muñoz Bello (2012), los traductores se encontraban ante varios panoramas a la hora de trasvasar los términos de una lengua a otra: algunos traductores adaptaban aquellos de origen griego a la ortografía de la lengua de llegada; otros debían decidir si preferían voces semejantes a las francesas, de manera que toda la terminología química fuese similar en todos los países, o bien si debían realizar adaptaciones para que fuesen más acordes a la lengua meta. Asimismo, también apuntan a la propuesta de nuevas voces para reemplazar algunas propuestas por los químicos franceses, cuestionadas como inadecuadas por el resto de los es- 
pecialistas de la época, pues no debemos olvidar que esta función es capital para normalizar y homogeneizar la terminología de la recién creada lengua vitivinícola.

Ahora bien, cabe preguntarse qué perfil tenían los traductores que debían hacer frente a este tipo de problemas terminológicos, así como a las posibles dificultades que plantea la traducción de un texto científico-técnico en general. En este sentido, Pickford (2012: 167) señala que se trataba, en general, de un experto del ámbito con competencias lingüísticas en la lengua origen y que realizaba traducciones de manera ocasional, con el fin de difundir el progreso científico (Bret, 2012: 954). De esta manera, encontramos a expertos en el ámbito en cuestión con conocimientos de la lengua extranjera, pero sin formación en traducción. Asimismo, como indica Olivier-Bonfils (2016), los traductores a menudo manipulaban a su conveniencia el texto original, lo cual ha dado lugar a que, en determinados casos, la traducción provocase las protestas de los autores. No obstante, a pesar de estos casos, debemos coincidir con Bertomeu y Muñoz (2012), cuando afirman que los traductores, a menudo poco conocidos, tuvieron un papel capital en la circulación, adaptación y en el rechazo de nuevos términos en las distintas lenguas europeas, ya que actúan como mediadores lingüísticos y dinamizadores de la ciencia, permitiendo numerosos adelantos y la llegada de nuevos conocimientos al país receptor.

\section{Objetivos y metodología}

En el presente artículo se abordará el análisis de la traducción a francés de la obra Ensayo sobre las variedades de la vid común que vegetan en Andalucía (1807) de Simón de Rojas Clemente y Rubio, publicada, en 1814, con el título Essai sur les variétés de la vigne qui végètent en Andalousie en Francia. Para ello, realizaremos un estudio comparativo que ponga en evidencia las principales técnicas de traducción empleadas en su trasvase, así como los principales problemas de traducción y sus respectivas soluciones a los que tuvo que hacer frente el traductor, el marqués de Caumels. Para la consecución de este fin, seguiremos a Hurtado Albir (2001), quien ya ha puesto de manifiesto que, en el ámbito de la traducción, existe una multiplicidad de soluciones que deberán adecuarse al contexto comunicativo determinado, por lo cual no es fácil determinar si una técnica de traducción es más eficaz que otra sin tener en cuenta el tipo de texto y el género textual, el contexto, la naturaleza del receptor, la finalidad de la traducción y las relaciones establecidas entre ambas culturas. Además, prestaremos atención al trasvase de los posibles elementos culturales que pudieran existir en la obra, conocidos como culturemas, que define Molina Martínez (2001: 89), como "[...] un elemento verbal o paraverbal que posee una carga cultural específica en una cultura y que al entrar en contacto con otra cultura a través de la traducción puede provocar un problema de índole cultural entre los textos origen y meta”. 
Anales de Filología Francesa, n. ${ }^{\circ}$ 27, 2019

UN ACERCAMIENTO AL INTERÉS POR LA VITICULTURA EN EL SIGLO XIX: A PROPÓSITO DE LA...

\section{El Ensayo sobre las variedades de la vid común que vegetan en Andalucía y su traducción a francés}

\subsection{Consideraciones en torno al autor y al traductor}

El Ensayo sobre las variedades de la vid común que vegetan en Andalucía de Simón Clemente y Rojas fue un tratado publicado, en primer lugar, en forma de artículos en el Semanario de Agricultura de Francisco Antonio Zea, y posteriormente en forma de libro en 1807 (Martín, 2010). Se trata, además, de una de las obras de carácter enológico que más repercusión tuvo no solo en su país de origen, sino también en otras muchas potencias europeas de la época, teniendo en cuenta que a los pocos años de su publicación fue editada en Francia (1814) y en Alemania (1821). De hecho, como señala Martín (2010), esta obra en concreto llegará a Alemania a partir de su traducción francesa, lo cual da cuenta de la capacidad de Francia como país exportador de conocimientos científicos y de la condición del francés como lingua franca de la época.

La figura de Clemente y Rubio se encuentra particularmente bien documentada, gracias a lo cual podemos conocer con exactitud una gran cantidad de datos biográficos que nos permiten comprender mejor las características de sus tratados. Piqueras Haba (2013) señala que su nacimiento tuvo lugar el 27 de septiembre de 1777 en Titaguas (Valencia) en una familia de labradores relativamente acomodada. Al ser el cuarto de los hijos de la familia, sus padres decidieron que la mejor opción para Clemente y Rubio sería la carrera eclesiástica, por lo que ingresó en el Seminario de Segorbe a los diez años. Si bien, como indica este autor, al quedar demostrada su escasa vocación sacerdotal y sintiéndose más atraído por las ciencias de la naturaleza, abandonará el seminario. Con 23 años, comenzó a realizar sustituciones en el Colegio de San Isidro, donde asistió a clases de árabe, botánica, mineralogía y química, entrando en contacto con personajes insignes como Casimiro Gómez de Ortega, botánico y primer catedrático del Jardín Botánico de Madrid. Posteriormente, recibiría un encargo de Manuel Godoy para realizar un estudio sobre las producciones y la historia natural del Reino de Granada durante cuatro años, siendo guardados sus trabajos en el Jardín Botánico de Madrid. De hecho, su relación con Godoy se aprecia en la dedicatoria del Ensayo, ya que se ofrece al Serenísimo Señor Príncipe Generalísimo Almirante, quien:

[...] me apartó de las tareas estériles y misantrópicas de Colegios y Universidades: que me empeño en la carrera de las ciencias útiles: que me hizo ver los sabios y la Europa; y que siendo forzoso dexaje yo de concurrir á la empresa capital, á que su genio superior me había destinado, se dignó conducirme baxo su protección é explorar las desconocidas riquezas y primores de Granada [...] (1807: II).

Tras esto, ocupó el puesto de bibliotecario en el Jardín Botánico de Madrid, donde, junto con Mariano Lagasca, realizaron diversas tareas como la catalogación de colecciones 
de plantas americanas realizadas por José Celestino Mutis en Bogotá; así como la edición del tratado de Agricultura general de Alonso Herrera por la Sociedad Económica Matritense y actualizarla con adiciones de rigor científico y actualidad. Asimismo, formó parte de las comisiones de Agricultura, Salud e Instrucción Pública tras el pronunciamiento de Riego de 1820 y el restablecimiento de la Constitución de Cádiz. Varios años más tarde, fallecería en Madrid en 1827 de fiebre amarilla. Martín Polo (2010), además, realiza un compendio de las obras publicadas por Clemente y Rubio a lo largo de su vida y póstumamente (2010: 753756): la primera, datada de 1801, es de carácter lingüístico: Pequeño alarde de la Gramática y Poética arábiga que ofrece al examen y curiosidad pública en los Reales Estudios de Madrid. No obstante, el grueso de su obra está formado por tratados de carácter agrónomo y botánico, como Introducción a la criptogamia española (1802) junto con Lagasca y García, Memoria sobre el cultivo y cosecha del algodón en general y con aplicación a España, particularmente a Motril (1818), Reglas para el cultivo del algodón (1821) y Tentativa sobre la liquenología geográfica de Andalucía (1863).

Sin embargo, la información relativa al traductor de la obra, el marqués de Caumels, es francamente escasa. No tenemos constancia de las fechas de su nacimiento o de su muerte ni otros apuntes biográficos detallados; si bien es cierto que en la obra Culture de l'arachidna, traduction d'un manuscrit espagnol (1821), realizada por este mismo traductor, se presenta al marqués de Caumels como colonel de cavalerie, chevalier de l'ordre royal et militaire de Saint-Louis de la société royal d'agriculture de Toulouse. De ello se desprende que se trataba de un personaje insigne de la época de la ciudad de Toulouse, tanto por su título nobiliario como por el resto de los cargos que ostentó a lo largo de su vida. La consulta de ciertas obras de la época nos permite afirmar que se trataba de un hombre instruido y conocedor de la botánica y de la vinicultura, ya que, como indica Rougier de la Bergerie (1822: 136-139):

[...] à peu près vers la même époque $M$. le marquis de Caumels, de Toulouse, me fit part des graines de la même plante qu'il avait reçues de Valence en Espagne ; je les ai cultivées comparativement avec celles que je tenais de votre complaisance. [...] M. le marquis de Caumels me parlait ensuite de la culture de cette plante, et entrait dans d'assez longs détails à cet égard, comme ses préceptes sont à peu près les mêmes que ceux consignés dans une brochure qu'il a dernièrement traduite de l'espagnol et que vous pouvez avoir a votre disposition [...].

Asimismo, como se podrá observar más adelante, el marqués de Caumels deja constancia en la obra de sus conocimientos en botánica a partir de la incorporación de notas del traductor, mediante las cuales complementa la obra de Clemente. De esta manera, siguiendo los estudios de Pickford (2012) y Bret (2012), el marqués de Caumels se puede clasificar en este grupo de expertos en la materia con conocimientos lingüísticos en un par de lenguas concreto, que se dedicaban a traducir obras foráneas con el fin de difundir el conocimiento científico en sus países. 


\subsection{Consideraciones en torno al Ensayo sobre las variedades de la vid común que vegetan en Andalucía y su traducción a francés}

La obra traducida presenta una serie de diferencias con respecto al texto original que conviene señalar. En primer lugar, se omite en la portada la reseña biográfica del autor, en la que se especifica que es "bibliotecario del Real Jardín Botánico de Madrid, individuo de las Reales Sociedades Económicas de Granada y Sanlúcar de Barrameda”, la cual es seguida por un fragmento de las Georgias de Virgilio. La versión francesa continúa con un breve epílogo del traductor, en el que se invita a los viticultores a leer el tratado debido a los avances que presenta en el ámbito del cultivo de la vid:

Les progrès de la botanique n'ont pas encore répondu aux besoins et aux vœux des cultivateurs de la vigne. [...] Nous invitons les cultivateurs de la vigne à profiter des excellens [sic] principes contenus dans cet Essai. Ils doivent être convaincus qu'il est impossible d'obtenir de cette plante précieuse tous les avantages qu'on peut en retirer, sans la connaître et savoir distinguer ses variétés.

Asimismo, en el Préface, el traductor explica brevemente el proceso de traducción que ha seguido para trasvasar la terminología vitícola y, en particular, el nombre de las variedades que Clemente acuña:

J'ai conservé les noms espagnols que M. Clemente donne à ses variétés, j'aurais craint, en les rapprochant de l'idiome français, de multiplier les difficultés de la synonymie. J'ai aussi traduit les noms qu'il a donnés à certains caractères de la vigne, dans l'expression la plus rapprochée de celle qu'il a choisie. Si MM. Les botanistes en trouvent de meilleurs, je me ferais un devoir de les adopter et de me conformer à leur avis.

De esta manera, podemos observar que el traductor justifica la elección de uno $u$ otro término y expone una de sus decisiones de traducción, que consistirá en preservar la nomenclatura original de Clemente y Rojas cuando sea posible, dado que son variedades localizadas en el sur de España. De esta manera, de Caumels se muestra consciente de la problemática del trasvase de la terminología de una lengua fuente a la lengua meta y de los problemas asociados a ella, como la sinonimia y la falta de estandarización. Asimismo, en la última parte de su epílogo, el marqués de Caumels hace uso del recurso conocido como captatio benevolentiae, propio de los prefacios e introducciones, mediante el que se excusa y se compromete a rectificar las posibles inexactitudes que pudiera contener la obra. De hecho, en la introducción del Ensayo, el propio autor hará uso de este mecanismo, como se puede observar en el siguiente fragmento de la obra:

Son absolutamente inevitables tales aberraciones, y mas en la vid, que transmigrando por diversos climas y cultivada de mil modos y por largos siglos se ha desfigurado 
tan prodigiosamente sin que en el examen y determinación de sus muchas variedades se haya dado se haya dado hasta Du Hamel un paso con aciertos. Somos, sin duda, él y yo los primeros que hemos tratado científicamente de la vid; pero ninguno puede lisongearse de haber evitado todo error. No se perfeccionan estas obras sino á fuerza de multiplicar y repetir observaciones, y es indispensable, ó publicarlas con todos sus defectos, ó mantenerlas sepultadas largas años, para irlas cada dia corrigiendo y sucesivamente reformando. Me hubiera decidido por este partido, si mi destino en Madrid y los empeños que tengo contraídos con el Gobierno y con el público, no me quitasen ya toda esperanza de volver á Andalucía á examinar segunda vez con mejor conocimiento todos los vidueños que describo. No siéndome pues dado corregir por mí mismo los errores de una obra en que tanto he trabajado y hecho trabajar á mis amigos ( i ), solo aspiro á que otros la corrijan ó me ayuden á perfeccionarla. Con este solo objeto la publico, y no se me puede hacer mayor favor que indicarme qualquier falta, ó suministrarme observaciones y noticias que me la hagan reconocer. Entretanto iré examinando otras variedades, y si logro que los hombres instruidos y amantes del bien general me proporcionen los objetos y datos que solicito, podré emprender la monografía completa de la vid: obra difícil, pero tan importante para nuestra Agricultura, que sin ella no hay que esperar grandes adelantamientos en tan precioso ramo (Clemente, 1807: 16).

En lo que respecta a la macroestructura, el libro original se encuentra dividido en esta breve nota, seguida de una introducción, en la que se exponen las razones por las que Clemente y Rojo se encaminó hacia los estudios agrícolas y los motivos que le llevaron a redactar el tratado:
¿No es claro que mientras no tengamos exactas descripciones de los vidueños[sic] culti- vados en diversos países [sic], ignoraremos los que nos faltan, no sabremos apreciar los que tenemos, y nos será difícil ó imposible imitar los buenos vinos extranjeros [sic], quando [sic] tal vez adquirida la casta que los da, llegaríamos por la superioridad de nuestro clima á ser los árbitros [sic] de su comercio? [...]. El hecho es, que convencido de la importancia de un tratado sobre las variedades de la vid, y de la razon [sic] con que se queja el público de la inutilidad de los Botánicos, me resolví á emprender una obra que aunque imperfecta, no dexaria $[$ sic $]$ de contribuir al adelantamiento de tan precioso ramo de nuestra Agricultura y de justificar la ciencia que profeso en el tribunal de la opinión (Clemente y Rojas, 1807: XI-XII).

Este Ensayo se escribe, además, como un intento por poner orden en los estudios en botánica que existían hasta la fecha, considerando, especialmente, las inconsistencias y confusiones que existía en este ámbito en la época:

Apenas había [sic] comenzado á estudiar algunos vidueños en la naturaleza y en los libros, quando advertí el desorden y la inconseqüencia que reynaba en todas las ideas. Habiase hecho aprecio de caracteres insubsistentes desconociéndose los verdaderos: hallábanse confundidas especies y variedades: la misma definición de la vid, admitida por todos los Botánicos, era enteramente esa: todo en fin estaba mal concebido o absolutamente ignorado, y todo por hacer. No pudiendo ya prometerme algún acierto sino á fuerza de ver y comparar objetos, recorrí hasta Conil todas las viñas de la costa, 
y sucesivamente las de Trebugena, Xerez, Espera, Paxarete y Bornos, restituyéndome siempre á mi mansión querida, en donde estudiaba tranquila y deliciosamente las variedades que iba describiendo.

A la introducción de la obra le sigue una primera parte, formada por los preliminares (capítulos I-VI) centrados en los terrenos andaluces en los que se cultiva la vid común, en la que se incluye la exposición de los caracteres que pueden ayudar a distinguir las variedades de la vid común. La segunda parte presenta una tabla sinóptica de las variedades, considerada, en términos del autor, como una parte práctica, a la que sigue una "Instrucción sobre los medios de que pueden valerse los que quieran contribuir á la formación de un tratado completo sobre los vidueños [sic] de España". Finaliza la obra con un "Índice de los sinónimos, nombres vulgares y otros que se han dado o dan a las especies y variedades de la vid, y se sientan en esta Obra", el "Índice de palabras y materias", la sección titulada "Etimologías de varias voces españolas usadas en esta obra" y "Listas de plantas" nombradas a lo largo de la obra. Estas dos últimas partes, sin embargo, no han sido traducidas en la versión que hemos estudiado de 1814, ya sea por decisión del traductor o, posiblemente, del editor.

Contemplados estos aspectos, cabe preguntarse qué calidad posee la traducción al francés de esta obra en particular de Clemente y Rubio. Para ello, hemos procedido a analizar la versión original del tratado de Clemente de 1807 y la edición francesa de 1814. A tenor de los resultados del análisis comparativo, podemos decir que el traductor ha realizado un trasvase óptimo del texto origen. No obstante, existe una serie de divergencias entre las dos versiones que consideramos interesante señalar, como la significativa reducción de notas al pie del autor en la versión original, un total de 209, frente a las 175 de la versión francesa. Asimismo, se han incluido cuatro notas al pie adicionales, tres de ellas indicadas con la mención "note du trad." salvo la última, lo cual podría deberse a dos razones: 1) se trata de una nota del traductor no especificada o 2) se trata de una nota del editor, ya que, en ella, como veremos a continuación, se hace un alegato a favor de los estudios de la vid francesa con el fin de progresar en la ampelografía nacional. Debemos tener en cuenta que, como señalan Pinilla y Lépinette (2009: 124), estas notas son un nuevo texto creado por el traductor, mediante el cual se completa, contradice o precisa la traducción, creando, así, un discurso plural o como lo denominan estas autoras, una "suerte de diálogo entre el autor y el traductor", alejada de la categoría de la adaptación traductológica. En este caso en concreto, estas notas del traductor dan cuenta de los avanzados conocimientos del marqués de Caumels en el ámbito de la botánica y de la viticultura, ya que pretende enriquecer la información que se aporta en el tratado:

II est démontré que les différentes espèces ou variétés de la vigne ne réussissent pas également dans toutes sortes de terreins. Ainsi il serait très-utile de se procurer l'analyse des terres dans lesquelles on la cultive, ou qu'on désire la planter. La bonté du climat, l'avantage d'une bonne exposition ne suffisent pas. Pour assurer les succès 
du cultivateur, il faut encore que la nature du terrein soit propre aux espèces qu'on y cultive (De Caumels, 1814: 6).

Il est aisé de se convaincre de la vérité de cette assertion, en observant après la floraison, la formation des vrilles. J'en ai cueilli dont toutes les extrémités portaient un grain bien formé ; leurs divisions étaient absolument les mêmes que celles des raisins qui croissaient sur la même souche ; et ces vrilles n'étaient absolument que des squelettes du raisin, dont les parties s'étaient excessivement prolongées (De Caumels, 1814: 54-55).

La última nota al pie se encuentra en el capítulo "Instrucción sobre los medios de que pueden valerse los que quieran contribuir á [sic] la formación de un tratado completo sobre los vidueños [sic] de España” en el que Clemente y Rojas propone crear unos estudios de ampelografía española:

\begin{abstract}
Ni es de esperar que este depósito precioso llegue á entrar en la masa general de luces mientras sea tan rara entre nuestros sabios del campo la habilidad de hacerlo estimar por medio de la escritura, tan raros los viages agronómicos, y en suma tan poco activo el comercio de ideas entre el labrador practico y los literatos que saben apreciar la dignidad del arte. Facilitar este comercio en uno de los ramos que mas interesan á la prosperidad nacional, en que no se sabe si admirar mas la inteligencia y exquisitos conocimientos de algunas provincias nuestras ó la ignorancia y errores capitales de otras, y en que tanto tenemos todos que aprender y que adelantar; tal es el grande objeto á que se han dirigido principalmente todos mis esfuerzos en la formación del ENSAYO. ¡O si lograse coronarios un día publicando la Ampelografia española ó tratado completo de los vidueños que se cultivan en España. (1807: 258).
\end{abstract}

En este caso, el traductor o el editor apoyan dicha idea y pugnan por llevarla a cabo en Francia: "Nous formons le même vœu pour la France. Si chaque propriétaire se donnait la peine d'examiner un seul cépage, nous verrions bientôt l'ampélographie française".

A la omisión de casi 35 notas al pie en la obra traducida debemos sumarle otras omisiones en el cuerpo del texto como se puede observar en el siguiente fragmento, en el cual se ha eludido en francés la oración en la que se recoge la denominación de tierra "tosca":

La albariza contiene desde sesenta á setenta por ciento de carbonate de cal, y al parecer bastante arcilla, un poco de sílice, y acaso algo de magnesia. Tal es la proporción que por lo general guarda el carbonate calizo en esta tierra, según el ensayo analítico que ha hecho de ella D. Luis Proust: pero en algunos parages es mayor todavía, y en otros apenas contiene el terreno mas que el carbonate casi puro; en cuyo caso ya no quieren los naturales darle el nombre de tosca. (1807: 3-4).

Cette terre blanche contient de 60 à 70 pour cent de carbonate de chaux, assez d'argile en apparence, un peu de silice, et quelquefois un peu de magnésie ; telle est la proportion que conserve généralement le carbonate de chaux dans cette terre, selon l'essai analytique qu'en a fait don Louis Proust. Mais, dans certains parages, elle est encore 
plus grande, et dans quelques-uns le terrain ne contient que du carbonate quasi pur (1814: 7).

Asimismo, hemos detectado adiciones del traductor en el texto origen, como notas al pie que no existían en la versión original, cuya finalidad principal ha sido proporcionar una definición de términos poco conocidos como "geognóstico" y "oritognosia" (1814: 5). Las adiciones han sido también una técnica usada por el traductor, quien ha incluido información a menudo relacionada con aspectos terminológicos en el cuerpo del texto:

Estas dos propiedades de echar agracejo y uva menuda se expresan en el Reyno de Granada con el verbo alherear ó alhelear, y en Castilla con los de lardear, ardalear y ralear (1807: 47).

Ces deux propriétés de donner du verjus et des petits grains, et ceux de donner des raisins très-clairs, s'expriment dans le royaume de Grenade parle verbe alherear, et en Castille, par lardear (c'est-à-dire, qui s'éclaircit) (1814: 84).

Por otro lado, hemos observado una cierta confusión en la traducción de las denominaciones de las variedades de vid y uva en francés. En este sentido, hemos hallado cuatro técnicas distintas en la traducción de la denominación de la uva o de la cepa: 1) traducción completa; 2) traducción parcial; 3 ) adaptación a la pronunciación francesa; 4) mantenimiento de la nomenclatura, respetando, como argumentó el traductor, el nombre de las variedades nombradas por Clemente. De esta manera, variedades como "Jaén negro de Sevilla" aparecen traducidas como "Jaen, noir de Séville", mientras que otras como "casta de Ohanez", "mollar blanco" o "vigiriega" mantienen el término original en la edición francesa. En otras cepas, en cambio, hallamos adaptaciones parciales, como es el caso de "polop dulce", traducido como "polop doux". Finalmente, encontramos una adaptación de los nombres a la fonética francesa, como es el caso de "Pedro Ximénez", traducido como "pédroximènes". No obstante, este último es un ejemplo de la falta de coherencia de la traducción, ya que en la obra aparecen las denominaciones "pedroximènes", "pédroximènes" y "Pierre ximènes" para la misma variedad.

Asimismo, como indicó previamente el traductor, las 36 nuevas variedades halladas y nombradas por Clemente y Rojas en honor a personajes ilustres de la época, botánicos en su mayoría, no han sido traducidas a francés. En la Tabla 1 recogemos una muestra dichas denominaciones: 


\begin{tabular}{|c|c|c|c|}
\hline $\begin{array}{l}\text { Nomenclatura en } \\
\text { español }\end{array}$ & $\begin{array}{l}\text { Nomenclatura en } \\
\text { francés }\end{array}$ & Origen de la nomenclatura & Página \\
\hline Colgadera - Ligeri & Colgadera - Ligeri & $\begin{array}{l}\text { Señor Liger, autor de La nouvelle } \\
\text { maison rustique. }\end{array}$ & 137 \\
\hline $\begin{array}{l}\text { De Fuentedueña - } \\
\text { Fuenteduennae }\end{array}$ & $\begin{array}{l}\text { Defuente Duena - } \\
\text { Fuente duenae }\end{array}$ & $\begin{array}{l}\text { Cosme Martín de Fuentedueña, } \\
\text { botánico y autor del tratado Agricul- } \\
\text { tura práctica. }\end{array}$ & 138 \\
\hline $\begin{array}{l}\text { Tempranillo }-\mathrm{Cu}- \\
\text { pani }\end{array}$ & Tempranillo - Cupani & Francesco Cupani, botánico italiano. & 138 \\
\hline $\begin{array}{l}\text { Jaén negro de Sevil- } \\
\text { la - Stephani }\end{array}$ & $\begin{array}{l}\text { Jaën noir de Séville - } \\
\text { Stephani }\end{array}$ & $\begin{array}{l}\text { Carlos Estienne, uno de los autores } \\
\text { de la Casa rústica. }\end{array}$ & 147 \\
\hline $\begin{array}{l}\text { Jaén negro de Gra- } \\
\text { nada - Crescencii }\end{array}$ & $\begin{array}{l}\text { Jaën noir de Grenade } \\
\text { - Crecencii }\end{array}$ & $\begin{array}{l}\text { Pedro de Crescenciis, llamado vul- } \\
\text { garmente Crescentino. Senador de } \\
\text { Bolonia, labrador y botánico. }\end{array}$ & 148 \\
\hline $\begin{array}{l}\text { Jaén Blanco - Var- } \\
\text { ronis }\end{array}$ & Jaen blanc - Varronis & $\begin{array}{l}\text { Varron, agrónomo, al que describe } \\
\text { como "el más sabio de los Roma- } \\
\text { nos, ilustre labrador, de quien se } \\
\text { ha dicho que hizo á la Agricultura } \\
\text { eloqüente" (1807: 74) }\end{array}$ & \\
\hline $\begin{array}{l}\text { Mollar negro bravío } \\
\text {-Duhamelii }\end{array}$ & $\begin{array}{l}\text { Mollar noir sauvage - } \\
\text { Duhamelii }\end{array}$ & $\begin{array}{l}\text { Henri-Louis Du Hamel Du Mon- } \\
\text { ceau, botánico, químico y agróno- } \\
\text { mo francés. }\end{array}$ & 153 \\
\hline $\begin{array}{l}\text { De Laleña - Lalen- } \\
\text { nae }\end{array}$ & $\begin{array}{l}\text { De Lalena - Lalen- } \\
\text { nae }\end{array}$ & $\begin{array}{l}\text { Cecilio García de la Peña, agróno- } \\
\text { mo español. }\end{array}$ & 156 \\
\hline $\begin{array}{l}\text { De Beguillet - Be- } \\
\text { guilleti }\end{array}$ & $\begin{array}{l}\text { De Beguillet - Be- } \\
\text { guilleti }\end{array}$ & $\begin{array}{l}\text { E. Beguillet, agrónomo e historiador } \\
\text { francés. }\end{array}$ & 156 \\
\hline $\begin{array}{l}\text { Albillo pardo - } \\
\text { Heppe }\end{array}$ & Albillo gris - Heppe & $\begin{array}{l}\text { Jorge Heppe, autor del Ars propa- } \\
\text { gandi vites apud Francos usitata. }\end{array}$ & 157 \\
\hline $\begin{array}{l}\text { Albullo de Huelba - } \\
\text { Herrerae }\end{array}$ & $\begin{array}{l}\text { Albullo de Huelba - } \\
\text { Herrerae. }\end{array}$ & $\begin{array}{l}\text { Alonso de Herrera, padre de la am- } \\
\text { pelografía española. }\end{array}$ & 157 \\
\hline
\end{tabular}

Tabla 1. Ejemplos de nomenclaturas acuñadas por Clemente y Rojas y su traducción.

En lo que respecta al léxico del ámbito de la geología, el marqués de Caumels ha optado, en determinados casos, por acompañar su traducción del término original en castellano, como "Barros, terre glaises" y "terreras, tertres". En otros casos, el traductor ofrecerá un equivalente, como "Lantejuela", que ha sido trasvasados por "paillette". No obstante, términos geológicos, como arenas, serán traducidos mediante un equivalente, en este caso, "sable". 
Asimismo, junto con la terminología propiamente botánica, el traductor tuvo que lidiar con una serie de términos culturales, o culturemas, como la arroba - la unidad de masa usada en la península Ibérica e Hispanoamérica, cuyo peso equivalía a 11,502 kg —, traducida por "quintal". La falta de estandarización de las unidades de medida ha supuesto un problema evidente al traductor, dado que había que proporcionar un equivalente y recalcular las cantidades en la edición francesa. Un ejemplo de elo se observa en los siguientes fragmentos donde aparecen las unidades de medida "aranzadas" "estadales" y "vara" y, en francés, "mesure de terre", "toise carrée" y "pied".

En el término de Sanlucar se cuentan quatro mil aranzadas de viña. Cada aranzada comprende quatro cientos veinte y cinco estadales, ó seis mil y ochocientas varas quadradas. Las vides se plantan por lo común á distancia de vara y media ó dos varas (1807: 5). Dans le canton de San-Lucar on cultive quatre mille mesures de terres, de contenance de sept mille neuf cent trente-trois toises carrées chacune ; les souches se plantent ordinairement à distance de quatre pieds et demi à six pieds (1814:9)

\section{Conclusiones}

Francia se postuló entre los siglos XVIII y XIX como el faro cultural y científico en el continente europeo, especialmente en ciencias como la química, la medicina o la recién creada enología, que llegarán al resto de países, entre ellos España, mediante la actividad traductora. No obstante, a pesar de la dependencia y del retraso del país ibérico en el ámbito científico, en él se editan distintas obras de gran calidad que serán traducidos a distintas lenguas europeas y conocerán un gran éxito, como es el Ensayo sobre las variedades de la vid común que vegetan en Andalucía, el cual abrió, además, distintas líneas de investigación que darán lugar a otros estudios como los de Jullien (1816), centrados en todos los viñedos del planeta, o aquellos del naturalista Louis Augustin Bosc de la Académie des Sciences de Francia, quien había decidido describir las diferentes cepas que existen en los viñedos franceses.

Gracias a los estudios como el que presentamos podemos arrojar luz sobre un ámbito de gran interés en los Estudios de Traducción. De esta manera, entre otros aspectos, hemos podido perfilar la figura del marqués de Caumels, un noble que ostentaba una serie de cargos en la ciudad de Toulouse, y que se inscribía en el grupo de expertos en un ámbito específico que decidían embarcarse en la traducción de obras de su área de trabajo con el fin de facilitar la transmisión del conocimiento científico y de los descubrimientos que tuvieron lugar en otros países. Su figura, al igual que la de Clemente, era conocida y valorada en Francia, algo que podemos comprobar en la obra de Jullien (1816/1866), quien afirma que la denominación de la vid y de las variedades de uva no se encontraba, en la época, bien documentada, siendo el tratado de Clemente y Rubio "le seul ouvrage qui en traite avec quelques détails [...] et M. Caumels nous en a donné une excellente traduction" (1866: 11-12).

Como hemos visto, la intencionalidad del autor es ofrecer un tratado lo más completo 
posible que fuese de utilidad a todos los expertos del ámbito de la agronomía y la viticultura. En lo referente a la traducción estudiada en el presente artículo, queda patente la pericia y los amplios conocimientos que poseía el traductor de la temática abordada. Hemos observado una serie de inconsistencias en la traducción, como el uso de varias denominaciones para un único concepto, distintas técnicas de traducción para elementos de un mismo campo semántico, omisiones de información y de notas al pie e, incluso, adiciones. No obstante, el traductor ha dado cuenta de una preocupación por el trasvase de la terminología del español al francés, la cual será el germen de la Terminología y de futuros procesos de estandarización.

\section{Referencias bibliográficas}

Álvarez Jurado, Manuela. 2016. “Un acercamiento a la preocupación decimonónica por los fraudes alimentarios: La traducción y recepción en España del Dictionnaire des altérations et falsifications des substances alimentaires de Alphonse Chevallier" in Onomázein, vol. 33, 289-309.

Bajo Santiago, Francisca. 2006. "La terminología enológica del español en el s. XIX" in IbÁÑez RodríGuez, Miguel \& María Teresa SÁchez Nieto (eds.). El lenguaje de la vid y el vino y su traducción. Valladolid, Universidad de Valladolid, 167-194.

BARbIER, Antoine Alexandre. 1874. Dictionnaire des ouvrages anonymes. Paris, Paul Daffis.

Bertomeu Sánchez, José Ramón \& Rosa Muñoz Bello. 2012. "La terminología química durante el siglo XIX: Retos, polémicas y transformaciones" in Educación química, n 23(3), 405-410.

Bret, Patrice. 2012. "Sciences et Techniques” in Chevrel Yves, Lieven D'Hulst \& Christine Lombez (dir.). Histoire des traductions en langue française, XIXe siècle. Lagrasse, Verdier, 927-1007.

Browne, Janet. 2003. Charles Darwin: The Power of Place. Londres, Pimlico.

Cadet De Vaux, Antoine Alexis. 1801. L'Art de faire le vin d'après la doctrine de Chaptal. París, Décade Pholosophique Littéraire et Popitique.

Carbonell i Bravo, Francisco. 1829. Arte de hacer y conservar el vino con una noticia acerca la fabricación del vinagre. Barcelona, Antonio Brusi.

Castellet, Buenaventura. 1865. Enologia española ó tratado sobre los vinos de España y su bonificación. Barcelona, Imprenta de Gomez é Inglada.

Clemente y Rubio, Simón Rojas. 1821. Reglas para el cultivo del algodón. Valencia, Imprensa de José Ferrer de Orga.

Clemente y Rubio, Simón Rojas. 1807. Ensayo sobre las variedades de la vid común que vegetan en Andalucía con un índice etimológico y tres listas de plantas en que se caracterizan varias especies nuevas. Madrid, Imprenta de Villalpando.

Clemente y Rubio, Simón Rojas. 1814. Essai sur les variétes de la vigne qui végètent en Andalousie. [Traducción de marqués de Caumels]. Paris, De Poulet. 
Anales de Filología Francesa, n. ${ }^{\circ}$ 27, 2019

UN ACERCAMIENTO AL INTERÉS POR LA VITICULTURA EN EL SIGLO XIX: A PROPÓSITO DE LA...

Clemente y Rubio, Simón Rojas. 1807/1821. Versuch über die Varietäten des Weinstocks in Andalusien [Traducción alemana de Albert Von Mascon]. Gras, Franz Ferstl.

Clemente y Rubio, Simón Rojas. 1818. Memoria sobre el cultivo y cosecha del algodón en general y con aplicación a España, particularmente a Motril. Madrid, Imprenta Real.

Clemente y Rubio, Simón Rojas. 1863. "Tentativa sobre la liquenología geográfica de Andalucía", in Revista de los progresos de las Ciencias Exactas, Físicas y Naturales, t. 14, $39-58$.

Cónsul Jove, Francisco. 1786/2006. Memoria sobre el cultivo de los vinos y sobre los principales progresos de la fermentación vinosa, y otros conocimientos y operaciones que dan al vino la mejor perfección y permanencia. [Edición de Juan B. Olarte]. Badarán, Bodegas David Moreno.

Cubero Salmerón, José Ignacio. 2003. El libro de Agricultura de Al Awam. Consejería de Agricultura y Pesca, Junta de Andalucía, Servicio de Publicaciones y Divulgación.

De Caumels. 1821. Culture de l'arachidna, traduction d'un manuscrit espagnol. Toulouse, Imprimerie de Bellegarrigue.

De Herrera, Alonso. 1513/1818. Agricultura general. Edición de la Real Sociedad Económica Matritense. Madrid, Imprenta Real.

De la Bergerie, Rougier. 1822. Cours d'agriculture pratique ou l'agronome français, par une société de Savans, d'Agronomes et de Propriétaires fonciers. Paris, Audot.

De Villeneuve, Arnaud. 2011. Le Livre des Vins, traduit du latin, préfacé et annoté par Patrick Gifreu, Perpignan, Éditions de la Merci.

Hurtado Albir, Amparto. 2001/2011. Traducción y Traductología. Introducción a la Traductología. Madrid, Cátedra.

IbáÑez RodríGuez, Miguel. 2017. La traducción vitivinícola: Un caso particular de traducción especializada. Granada, Editorial Comares.

Jiménez Domingo María Elena \& Brigitte Lépinette. 2016. "Los traductores del ámbito de la medicina" in Lépinette, Brigitte \& Pinilla, Julia (eds.). Reconstruyendo el pasado de la traducción. A propósito de obras francesas especializadas, cientificas y técnicas en sus versiones españolas. Granada, Editorial Comares, 109-156.

Jullien, André. 1816/1866. Topographie de tous les vignobles connus contenant leur position géographique, l'indication du genre et de la qualité des produits de chaque cru, les lieux ou se font les chargements et le principal commerce des vins, le nom et la capacité des tonneaux et des mesures en usage, les moyens de transport ordinairement employés, les tarifs des douanes de France et des pays étrangers, etc. Paris, Librairie d'Agriculture et d'Horticulture de Mme. Ve. Bouchard-Huzard.

Lagasca, Mariano, Donato García \& Simón Clemente y Rubio. 1802. “Introducción a la criptogamia española" in Anales de ciencias naturales, tomo 5, n⿳⺈ 14, 135-215.

LAMELIN, Engelbert. 1630. L'avant-goust du vin. Déclaration de sa nature, faculté medicinale et alimentaire. Douay, Jean de Fampou. 
Larbaud, Valéry. 1946. Sous l'invocation de Saint Jérôme. Paris, Gallimard.

Martín Polo, Fernando. Simón de Rojas Clemente y Rubio. Vida y obra. El compromiso ilustrado. Tesis doctoral, Universitat de Barcelona.

Molina Martínez, Lucía. 2001. Análisis descriptivo de la traducción de los culturemas árabe-español Tesis doctoral, Universitat Autònoma de Barcelona.

NidA, Eugene. 1945. "Linguistics and Ethnology in Translation Problems" in Word, $\mathrm{n}^{\circ} 2$, 194-208.

Olivier-Bonfils, Delphine. 2016. "Un traducteur médical au XIXe siècle: Gustave Borginon et l'antisepsie" in Meta, $\mathrm{n}^{\circ}$ 61, 113-130. Doi:10.7202/1038688ar

Pan-Montojo, José. 1989. La vitivinicultura en España (1750-1988). Madrid, Ministerio de Agricultura, Pesca y Alimentación.

Peynaud, Eugene. 1988. Le vin et les jours. Paris, Bordas.

Pickford, Susan. 2012. “Traducteurs" in Chevrel, Yves, Lieven D’Hulst \& Christine Lombez (eds.). Histoire des traductions en langue française. XIXe siècle. Lagrasse, Verdier, $149-254$.

Pinilla, Julia \& Brigitte LépinetTe. 2009. "La aportación propia del traductor al texto científico-técnico traducido o el afán de divulgación de un saber foráneo. A propósito del paratexo en una traducción al español de H. L. Duhamel du Monceau (1700-1782)" in Cuadernos del Instituto de Historia de la Lengua, n 3, 109-125.

Piqueras Haba, Juan. 2002. "Gesta y vida de un insigne botánico” in Mètode, no 34, 35-69.

Puche Lorenzo, Miguel Ángel. 2016. "La lengua de la minería a través de las traducciones inglesas en el siglo XIX: un nuevo ejemplo de traducción oculta" in LÉPINETTE, Brigitte \& Julia Pinilla (eds.). Reconstruyendo el pasado de la traducción. A propósito de obras francesas especializadas, cientificas y técnicas en sus versiones españolas, Granada, Editorial Comares, 239-250.

Rodríguez Guerrero, José. 2013. "El Origen del Pseudo-arnaldiano Liber de vinis, Obra del magister Silvester (ca.1322-1328), y su Tradición Manuscrita en el Siglo XIV" in Azogue, 7, 44-74.

Rozier, François, Jean Claude Chaptal \& André Thouin. 1783. Cours complet d'Agriculture théorique, pratique, économique et de médecine rurale et vétérinaire ou dictionnaire universel. París, Delalain Fils.

Vandaele, Sylvie \& Eve-Marie Gendron-Pontbriand. 2014. "Des 'vilaines infidèles' à la postérité: traduction et retraduction de l'œuvre de Charles Darwin" in Pinilla Julia \& Brigitte LePINeTte (dir.). Traducción y difusión de la ciencia y la técnica en España (s. XVI$X I X)$. Valencia, Universitat de València/Institut universitari de llengües modernes aplicades (IULMA), 230-249. 
